\title{
Article \\ Functional Characterization of the Photosynthetic Machinery in Smicronix Galls on the Parasitic Plant Cuscuta campestris by JIP-Test
}

\author{
Lyuben Zagorchev ${ }^{1, *}$, Alexandra Atanasova ${ }^{1}$, Ivanela Albanova ${ }^{1}$, Anelia Traianova ${ }^{1}$, Petko Mladenov ${ }^{2}$, \\ Margarita Kouzmanova ${ }^{1}$, Vasilij Goltsev ${ }^{1}$, Hazem M. Kalaji ${ }^{3,4}{ }^{\mathbb{D}}$ and Denitsa Teofanova ${ }^{1}$
}

1 Faculty of Biology, Sofia University "St. Kliment Ohridski", 8 Dragan Tsankov Blvd., 1164 Sofia, Bulgaria; atanassova.y@gmail.com (A.A.); albanova.ivanela@gmail.com (I.A.); a.traianova11@gmail.com (A.T.); mkouzmanova@gmail.com (M.K.); goltsev@gmail.com (V.G.); teofanova@biofac.uni-sofia.bg (D.T.)

2 AgroBioInstitute, Agricultural Academy, 8 Dragan Tsankov Blvd., 1164 Sofia, Bulgaria; rubisko@abv.bg

3 Institute of Biology, Warsaw University of Life Sciences-SGGW, 02-787 Warsaw, Poland; hazem@kalaji.p1

4 Institute of Technology and Life Sciences-National Research Institute, Falenty, Al. Hrabska 3, 05-090 Raszyn, Poland

* Correspondence: lzagorchev@biofac.uni-sofia.bg; Tel.: +359-898-211-635

\section{check for}

updates

Citation: Zagorchev, L.; Atanasova,

A.; Albanova, I.; Traianova, A.;

Mladenov, P.; Kouzmanova, M.;

Goltsev, V.; Kalaji, H.M.; Teofanova,

D. Functional Characterization of the

Photosynthetic Machinery in

Smicronix Galls on the Parasitic Plant

Cuscuta campestris by JIP-Test. Cells

2021, 10, 1399. https://doi.org/

10.3390/cells10061399

Academic Editor: Tatsuya Tomo

Received: 20 April 2021

Accepted: 3 June 2021

Published: 5 June 2021

Publisher's Note: MDPI stays neutral with regard to jurisdictional claims in published maps and institutional affiliations.

Copyright: (c) 2021 by the authors. Licensee MDPI, Basel, Switzerland. This article is an open access article distributed under the terms and conditions of the Creative Commons Attribution (CC BY) license (https:/ / creativecommons.org/licenses/by/ $4.0 /)$.
Abstract: Members of the genus Cuscuta are generally considered to be non-photosynthetic, stemholoparasitic flowering plants. Under certain circumstances, at least some members of the genus are capable of limited photosynthesis. The galls of the Smicronyx weevils formed on Cuscuta campestris are particularly rich in chlorophylls compared to the stem of the parasitic plant. In the present study, we aimed to characterize the photosynthetic activity in the inner and outer gall cortices in comparison to the non-photosynthetic stems and a reference plant (Arabidopsis thaliana). The recorded prompt chlorophyll fluorescence transients were analyzed using JIP test. Detailed analysis of the chlorophyll fluorescence confirmed the presence of actively functioning photosynthetic machinery, especially in the inner cortex of the galls. This photosynthesis, induced by the insect larvae, did not reach the levels of the photosynthetic activity in Arabidopsis thaliana plants. Thylakoid protein complexes were identified by separation with two-dimensional Blue Native/SDS PAGE. It appeared that some of the complexes presented in A. thaliana are missing in C. campestris. We hypothesize that the insect-triggered transition from non-photosynthetic to photosynthetic tissue in the gall is driven by the increased requirements for nutrients related to the larval nutrition.

Keywords: chlorophyll fluorescence; insect galls; JIP-test; parasitic plants

\section{Introduction}

Cuscuta campestris Yunck. (Convolvulaceae) is a stem-holoparasitic flowering plant with a broad host range. Originally from North America, it is currently distributed worldwide and considered a noxious weed [1]. A distinct characteristic of all members of the genus is their ability to acquire water, minerals, and organic nutrients through haustorial connection with the host's vascular system [2]. Because of that, members of the genus do not have functional leaves-leaves are completely missing or reduced to scales, and the plants are considered non-photosynthetic. Various sources reported a partial loss of photosynthesis-related genes, both in the nuclear genome and in the plastome [3-5].

Unlike other members of the genus, including the subgenus Grammica, C. campestris retained substantial part of the plastome genes [6]. In fact, no gene losses were detected in the sets for photosystems I and II, cytochrome $b_{6} / f$ complex, ATP synthase, or RuBisCO large subunit, but most of the NADH dehydrogenase genes were lost in this particular species. Furthermore, the nuclear genome of $C$. campestris retained all genes, needed for chlorophylls and carotenoids biosynthesis and most of the genes, needed for the linear and cyclic electron transport in the light-dependent photosynthetic reactions [7]. Therefore, 
C. campestris seems to contain chloroplasts and chlorophyll (Chl) concentrations, sufficient for at least limited photosynthesis as compared to fully non-photosynthetic C. odorata and C. grandiflora, but slightly weaker than C. reflexa [8]. However, this plant does not actually photosynthesize or at least does not do it at rates sufficient to sustain growth. It is logical that under optimal conditions, e.g., suitable host, when nutrients are readily available, it is unnecessary for the parasite to spend resources for photosynthetic activity. The photosynthetic ability, however, seems to be fully retained and may be triggered by various factors such as adaptable features to meet suboptimal conditions.

One such trigger was recently established-epiparasites of the genus Smicronyx (Coleoptera: Curculionidae), gall-forming insects, which prefer Cuscuta spp. as hosts [9]. Unlike other galls on photosynthetic plants where photosynthesis seems to decrease in the gall tissues [10], Smicronyx galls on C. campestris revealed much higher photosynthetic activity than non-infected Cuscuta stems [11]. It was also found that the inner cortex around the larval chamber is much more abundant in chlorophylls than the outer cortex or the stem [12]. Smicronix epiparasites are considered as a potential means for biological control of their agriculturally harmful hosts [13]. Although several reports on Smicronix gall formation in Cuscuta spp. exist, the metabolic and functional changes, occurring in the galls, remained largely unknown.

In the present study, we aimed to do a more detailed analysis of the light-dependent photosynthetic reactions in C. campestris stem in both the inner and outer cortex as compared to a fully photosynthesizing reference plant Arabidopsis thaliana. A. thaliana PSA has been studied in detail, its structure is well known, and it is the same as in the other green plants. Further, the thylakoid protein complexes in and outside the galls were investigated. Thus, both the elusive Smicronyx-Cuscuta interactions and the photosynthetic potential of C. campestris were considered.

\section{Materials and Methods}

\subsection{Plant Material}

Cuscuta campestris plants with Smicronyx sp. galls were collected in late June from a wild population in the village of Telish, Cherven Briag municipality, Pleven province, the Danubian plain, Bulgaria (GPS $43^{\circ} 19^{\prime} 27.3^{\prime \prime} \mathrm{N} 24^{\circ} 15^{\prime} 15.8^{\prime \prime}$ E). Plants were transferred with soil and with host plants together (mostly with Polygonum aviculare L. and Convolvulus arvensis L.) (Figure 1) into a greenhouse, adjacent to reference Arabidopsis thaliana plants. They were adapted for two days before further experiments. A voucher herbarium was deposited in the Herbarium SO (Sofia University "St. Kliment Ohridski", Sofia, Bulgaria) under herbarium number SO 107784.

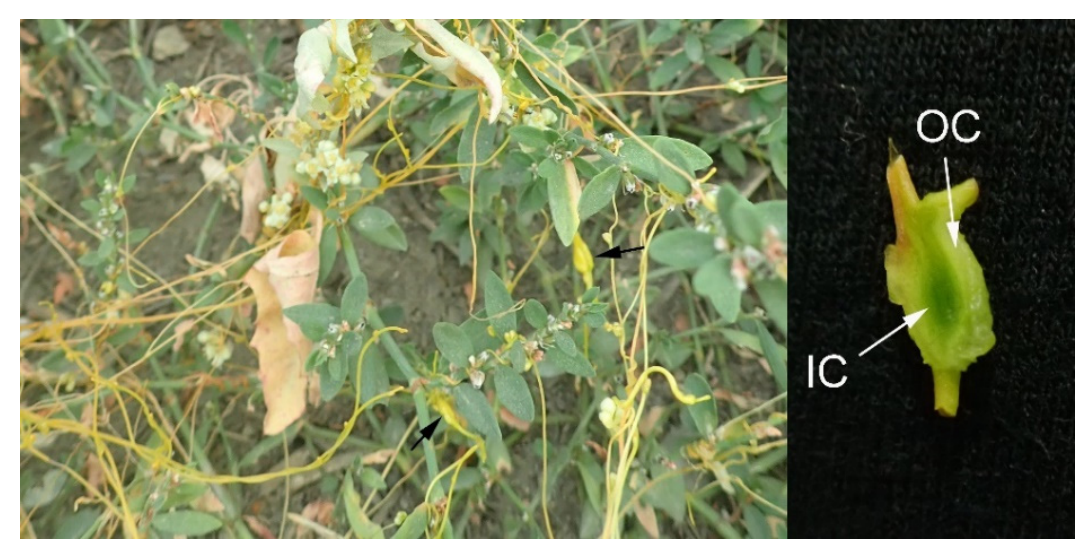

Figure 1. Yellowish stems of Cuscuta campestris on host Polygonum aviculare (left panel). Arrows indicate Smicronyx galls. Cross-section of a gall (right panel). The yellowish outer cortex (OC) and greenish inner cortex (IC) are indicated with arrows. 
The reference Arabidopsis thaliana L. plants, ecotype Columbia (Col-0), were grown from seeds, obtained from the Nottingham Arabidopsis Stock Centre, in greenhouse conditions, under illumination with Kingbo KB-GLX45 Full Spectrum LED light. Approximately three-week-old plants were used in further experiments.

\subsection{Chlorophyll a Fluorescence Measurement}

The prompt Chl $a$ fluorescence was measured using MPEA fluorometer (Multifunctional Plant Efficiency Analyzer, Hansatech Instruments Ltd., King's Lynn, UK) after a dark-adaptation for $60 \mathrm{~min}$. The PF measuring protocol included a $1 \mathrm{~s}$ pulse with high light intensity of $4000 \mu \mathrm{mol}$ photons $\mathrm{m}^{-2} \mathrm{~s}^{-1}$. Arabidopsis leaves were measured in vivo. Smicronyx sp. galls were cut into $2 \mathrm{~mm}$ thick slices, and the corresponding inner and outer cortices were measured separately. Cuscuta campestris stems were also measured, but the intensity of the fluorescence signal was comparable to the background noise of the electronic device, so the results are not shown.

\subsection{JIP-Test Parameters}

JIP-test parameters were calculated from the obtained data for Chl $a$ fluorescence based on the equations given by Strasser et al. [14] and Stirbet and Govindjee [15] and are presented in Table A1 in Appendix A.

\subsection{Difference Curves Calculations}

Every point on the double normalized curves of variable fluorescence was calculated by the equation (see Table A1):

$$
\mathrm{V}_{\mathrm{t}}=\left(\mathrm{F}_{\mathrm{t}}-\mathrm{F}_{\mathrm{O}}\right) /\left(\mathrm{F}_{\mathrm{M}}-\mathrm{F}_{\mathrm{O}}\right)
$$

where $V_{t}$ is a value of the relative variable fluorescence at moment $t ; F_{t}$-fluorescence level at that moment; $\mathrm{F}_{\mathrm{O}}$-minimal fluorescence level; $\mathrm{F}_{\mathrm{M}}$-maximal fluorescence level.

Each value of difference curves (DC) was calculated as a difference between the values of the relative variable fluorescence $\left[\mathrm{V}_{t}=\left(\mathrm{F}_{t}-\mathrm{F}_{\mathrm{O}}\right) /\left(\mathrm{F}_{\mathrm{M}}-\mathrm{F}_{\mathrm{O}}\right)\right]$ calculated for the investigated gall cortex minus the respective values for the reference plant $\left[\Delta \mathrm{V}_{\mathrm{t}}=\mathrm{V}_{\mathrm{t}}\right.$ (gall) $-\mathrm{V}_{\mathrm{t}}($ A. thaliana $\left.)\right]$.

DC for the characteristic phases of the induction curve $(\Delta W)$, calculated by subtracting the values of the IC for the control plants from the IC values of the stressed plants, are known as bands [14-16]. In this experiment, we calculated the differences in relative variable fluorescence values between gall cortices (inner or outer) and reference plant $A$. thaliana. There are four bands: $\mathrm{L}$ band (between $\mathrm{O}$ and $300 \mu \mathrm{s}, \Delta \mathrm{W}_{\mathrm{OK}}$ ), $\mathrm{K}$ band (between $\mathrm{O}$ and $\mathrm{J}, \Delta \mathrm{W}_{\mathrm{OJ}}$ ), $\mathrm{H}$ band (between $\mathrm{J}$ and $\mathrm{I}, \Delta \mathrm{W}_{\mathrm{JI}}$ ), and $\mathrm{G}$ band (between $\mathrm{I}$ and $\mathrm{P}, \Delta \mathrm{W}_{\mathrm{IP}}$ ), and their positive or negative values determine the efficiency and rate of different reactions at every stage of the process. $\Delta W$ was calculated for each band by double normalization of the raw PF signal at specific steps as follows:

For $\mathrm{O}-\mathrm{K}$ phase, L band:

$$
\mathrm{W}_{\mathrm{t}(\mathrm{OK})}=\left(\mathrm{F}_{\mathrm{t}}-\mathrm{F}_{\mathrm{O}}\right) /\left(\mathrm{F}_{\mathrm{K}}-\mathrm{F}_{\mathrm{O}}\right) ; \Delta \mathrm{W}_{\mathrm{OK}}=\mathrm{W}_{\mathrm{t}(\mathrm{OK})(\text { inner or outer cortex })}-\mathrm{W}_{\mathrm{t}(\mathrm{OK})(\text { A. thaliana })} ;
$$

For $\mathrm{O}-\mathrm{J}$ phase, $\mathrm{K}$ band:

$$
\mathrm{W}_{\mathrm{t}(\mathrm{OJ})}=\left(\mathrm{F}_{\mathrm{t}}-\mathrm{F}_{\mathrm{O}}\right) /\left(\mathrm{F}_{\mathrm{J}}-\mathrm{F}_{\mathrm{O}}\right) ; \Delta \mathrm{W}_{\mathrm{OJ}}=\mathrm{W}_{\mathrm{t}(\mathrm{OJ})(\text { inner or outer cortex })}-\mathrm{W}_{\mathrm{t}(\mathrm{OJ})(\text { A. thaliana })} ;
$$

For J-I phase, $\mathrm{H}$ band:

$$
\mathrm{W}_{\mathrm{t}(\mathrm{JI})}=\left(\mathrm{F}_{\mathrm{t}}-\mathrm{F}_{\mathrm{J}}\right) /\left(\mathrm{F}_{\mathrm{I}}-\mathrm{F}_{\mathrm{J}}\right) ; \Delta \mathrm{W}_{\mathrm{JI}}=\mathrm{W}_{\mathrm{t}(\mathrm{JI}) \text { (inner or outer cortex })}-\mathrm{W}_{\mathrm{t}(\mathrm{JI}) \text { (A. thaliana) }} \text {; }
$$

For I-P phase, G band:

$$
\mathrm{W}_{\mathrm{t}(\mathrm{IP})}=\left(\mathrm{F}_{\mathrm{t}}-\mathrm{F}_{\mathrm{I}}\right) /\left(\mathrm{F}_{\mathrm{P}}-\mathrm{F}_{\mathrm{I}}\right) ; \Delta \mathrm{W}_{\mathrm{IP}}=\mathrm{W}_{\mathrm{t}(\mathrm{IP}) \text { (inner or outer cortex })}-\mathrm{W}_{\mathrm{t}(\mathrm{IP})(\text { A. thaliana })} \text {. }
$$




\subsection{Statistical Analysis}

A total of seven galls (outer and inner cortex), and leaves of five individual A. thaliana plants were used for chlorophyll fluorescence transients recording. Average values of the induction curves and standard errors were calculated from seven repetitions for all the investigated objects.

\subsection{Thylakoid Protein Complexes Isolation and Separation}

Thylakoid protein complexes were isolated and solubilized essentially by the method of Järvi [17]. Due to a plant material availability limitation, however, several steps were omitted or modified in order to prevent losses. The inner and outer cortices of individual galls were sliced, weighted (10 mg each), and grounded in liquid nitrogen. Equal weights of Arabidopsis leaves and C. campestris stems were processed in parallel, all under dim green light. The resulting powder was resuspended successively in ice-cold grinding, shock, and storage buffers with $10 \mathrm{mM} \mathrm{NaF}$ [17] and centrifuged at $5000 \times g$ at $4{ }^{\circ} \mathrm{C}$ after each buffer. Filtration through Miracloth was omitted. Finally, the pellets were solubilized in $20 \mu \mathrm{L}$ $25 \mathrm{mM}$ BisTris $/ \mathrm{HCl}(\mathrm{pH} 7.0$ ) and 20\% (v/v) glycerol; supplemented with $1 \%(w / v)$ digitonin; shaken at room temperature for $10 \mathrm{~min}$; supplemented with $2 \mu \mathrm{L} 100 \mathrm{mM}$ BisTris/HCl ( $\mathrm{pH} 7.0), 30 \%(w / v)$ sucrose, and $50 \mathrm{mg} \mathrm{mL}^{-1}$ Coomassie Blue G buffer; and centrifuged for $10 \mathrm{~min}$ at $16,000 \times g$, and the whole amount was loaded onto Blue Native Polyacrylamide Gel Electrophoresis (BN-PAGE) system. Blue Native PAGE was performed on Cleaver Scientific vs. 10 electrophoresis system, $5-12.5 \%$ T gradient gels according to the protocol of Kügler [18]. Tricine-SDS PAGE in reducing conditions for the second dimension were performed on 15\% T gels according to Kügler [18], based on [19]. All samples were isolated and gels were run in triplicate.

\section{Results}

\subsection{Prompt Chlorophyll A Fluorescence}

The course of $\mathrm{Chl}$ a fluorescence transitions during its characteristic phases $\mathrm{O}-\mathrm{K}, \mathrm{O}-\mathrm{J}$, $\mathrm{J}-\mathrm{I}$, and I-P depends on the physiological state of the photosynthesizing object. Changes in the shape of induction curves can be visualized by calculation of differences in fluorescence values between investigated (gall cortex, inner or outer) and control (reference normal photosynthetic plant $A$. thaliana) objects-calculation of difference curves (DC) described by $[14,20]$. The differences in the IC shapes during the characteristic phases are manifested as specific bands in DC, named L band (between $\mathrm{O}$ and $\mathrm{K}(300 \mu \mathrm{s})$ ), $\mathrm{K}$ band $(\mathrm{O}-\mathrm{J}), \mathrm{H}$ band $(\mathrm{J}-\mathrm{I})$, and $\mathrm{G}$ band $(\mathrm{I}-\mathrm{P})$. We carried out a standard OJIP analysis of the prompt fluorescence induction curves and DC calculations in order to evaluate the photosynthetic activity in Smicronix galls on C. campestris.

The OJIP fluorescence rise reflects $Q_{A}$ reduction, with $Q_{A}$ equilibrium depending on the poise of the intersystem electron carriers, which, in turn, depends also on the redox state of P700 (PSI reaction center).

Induction curves showed significantly lower fluorescence of galls, especially of the outer cortex (Figure 2). From the two figures on the right, it can be seen that for the inner cortex $\mathrm{F}_{\mathrm{o}} \approx 5, \mathrm{~F}_{\mathrm{m}} \approx 17$, i.e., $\mathrm{F}_{\mathrm{v}} / \mathrm{F}_{\mathrm{o}} \approx 2.5$, while for the outer cortex $\mathrm{F}_{\mathrm{o}} \approx 2, \mathrm{~F}_{\mathrm{m}} \approx 5$, $\mathrm{F}_{\mathrm{v}} / \mathrm{F}_{\mathrm{o}} \approx 1.5$. This means less photosynthetic material in the outer cortex-lower concentration of photosynthesizing structures or a smaller amount of active photosynthesizing structures and photosynthetic membranes. 


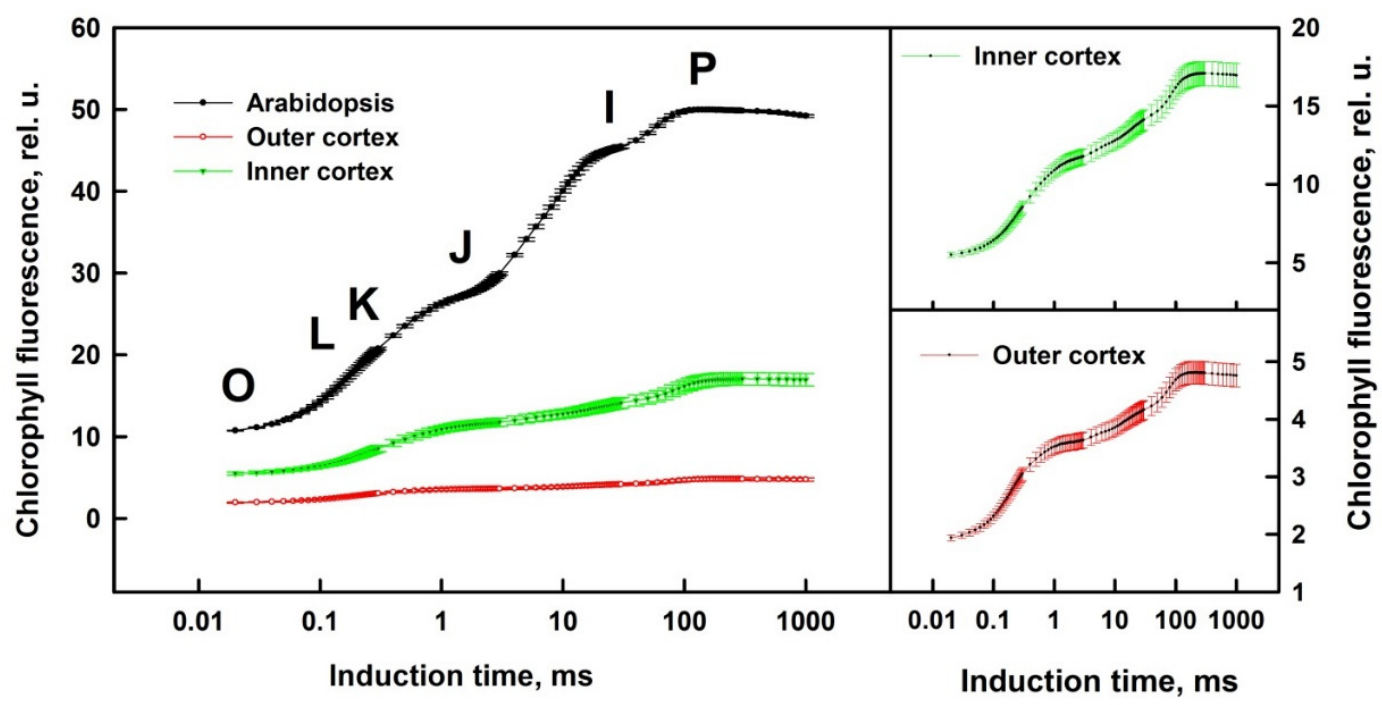

Figure 2. Induction curves recorded in inner and outer cortices of the Smicronix galls and in the leaves of reference photosynthetic plant $A$. thaliana (averaged over seven repetitions). The prompt fluorescence of the two cortices of the galls was measured in about $2 \mathrm{~mm}$ thick slices. The IC for the inner cortex only is presented above on the right, and for the outer cortex only, below on the right. The ranges of the relative units on the y-axes of the two smaller graphics on the right are different so that the slopes can be visible.

$\mathrm{O}, \mathrm{J}, \mathrm{I}$, and $\mathrm{P}$ characteristic steps of $\mathrm{Chl} a$ fluorescence traces were used for calculations of different JIP-test parameters and estimation of structural and functional differences between inner and outer cortex of galls. Comparison of courses of normalized fluorescence traces by calculation of difference curves allows detailed evaluation of structural and functional differences in the investigated objects (Figure 3).

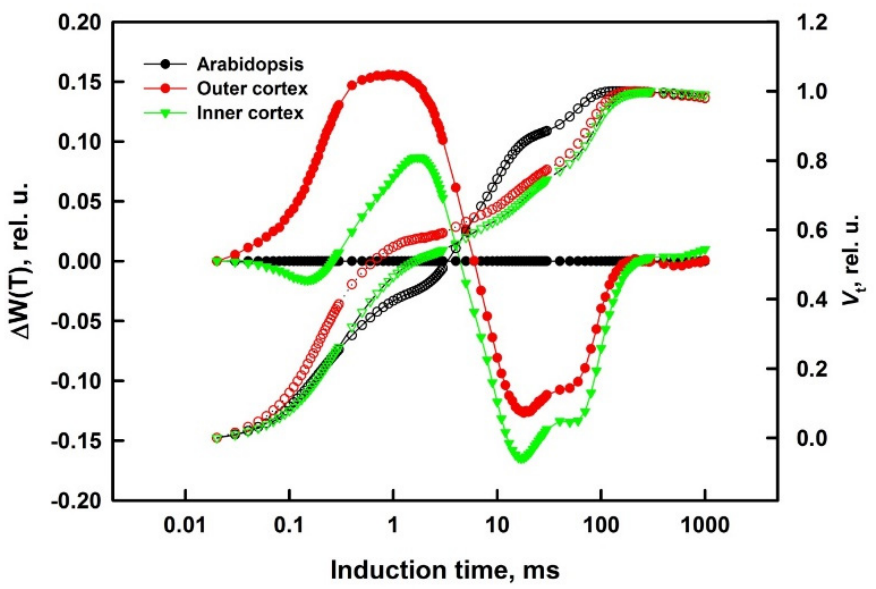

Figure 3. Double normalized curves presenting the relative variable fluorescence $\mathrm{V}_{\mathrm{t}}$ in $\mathrm{O}-\mathrm{P}$ transient of chlorophyll fluorescence, recorded in the cortex (inner or outer) of the Smicronix galls and in the reference normal photosynthetic plant $A$. thaliana (averaged over seven repetitions). The prompt fluorescence of the two cortices of the galls was measured in about $2 \mathrm{~mm}$ thick slices. The values of the relative fluorescence are presented on the right axis (empty symbols).

The OJIP fluorescence rise reflects $Q_{A}$ reduction, which depends on the poise of the intersystem electron carriers, which, in turn, is linked with the redox state of PSI reaction centre, P700. The main differences between the IC of gall cortex and the IC of $A$. thaliana leaves were significantly higher levels of the relative variable fluorescence during the initial phases of the transition (between 0 and $10 \mathrm{~ms}$ ) and a subsequent lag in its increase (10-300 ms) in gall cortices compared to A. thaliana (Figure 3). High values for 
$\mathrm{J}$ level indicate lower (or even blocked) electron flow in the acceptor side of PSII, more pronounced in the outer cortex (out).

Detailed analysis of the structural and functional differences in investigated objects could be done by comparison of the DC, calculated for the characteristic phases of the induction curve. Well-pronounced negative $\mathrm{L}, \mathrm{H}$, and $\mathrm{G}$ bands were manifested in the difference curves (Figure 4).

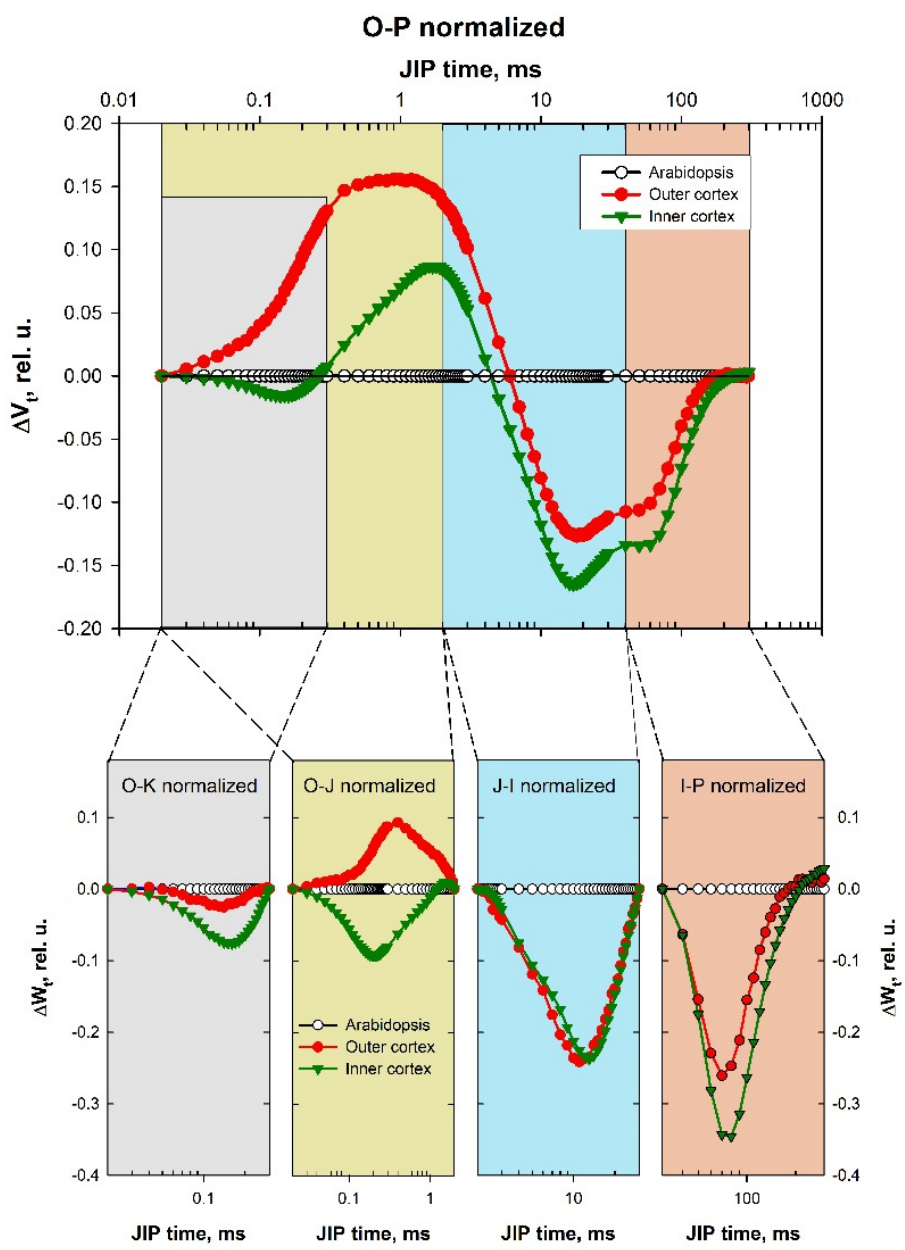

Figure 4. Difference curves showing differences in IC of PF between the gall cortex (inner or outer) and the reference plants $A$. thaliana. Each DC value was calculated as a difference between the values of the relative variable fluorescence $\left[\mathrm{V}_{\mathrm{t}}=\left(\mathrm{F}_{\mathrm{t}}-\mathrm{F}_{\mathrm{O}}\right) /\left(\mathrm{F}_{\mathrm{M}}-\mathrm{F}_{\mathrm{O}}\right)\right]$ in the gall cortex minus the respective values for the leaves of the reference plants A. thaliana $\left[\Delta \mathrm{V}_{\mathrm{t}}=\mathrm{V}_{\mathrm{t}(\text { cortex })}-\mathrm{Vt}_{(\text {A. thaliana })}\right]$. The four characteristic bands are marked with different colors (A). The four lower panels (B-E) represent the difference curves calculated for each band separately $\left(\Delta W_{t}\right)$. The equations for the calculations of the respective $\Delta W_{t}$ are presented in Materials and Methods.

\section{L band (O-K, $\mathrm{O}-300 \mu s)$}

The functionality of PSII (i.e., antenna size, connectivity between PSII RCs) depends on the pigment-protein complexes packing in the PSA [21]. The L band is associated with the arrangement of PSII units in the thylakoid grana membrane--"grouping", and with the "connectivity" of LHCII and PSII reaction centers [21,22]. The negative maximums of L bands indicated increasing grouping between neighboring PSII in thylakoid membranes. A negative $L$ peak is formed at a better possibility for energy transfer between adjacent antenna complexes of PSII when the antennae are better packed, or when they are larger and in contact with each other. Positive differences mean ungrouping of the antenna 
complexes [20]. The negative L-band values are particularly pronounced in the inner cortex (IC).

\section{$K$ band $(O-J, 20 \mu s-2 m s)$}

The $\mathrm{K}$ band reflects a photochemical reduction of $\mathrm{Q}_{\mathrm{A}}$ and partial reoxidation of $\mathrm{Q}_{\mathrm{A}}{ }^{-}$ by PQ (via $\mathrm{Q}_{\mathrm{B}}$ ). It gives information about the state of the donor side of PSII-the fraction of operating oxygen-evolving complexes (OEC) — and particularly about Mn-complex in PSII donor side [23-26]. It is a specific rise with a maximum at about $300 \mu$ s on the OJIP induction curve, which is mostly hidden between $\mathrm{O}$ and $\mathrm{J}$ in normal conditions but is often observed under heat or drought stress $[23,27]$. The $\mathrm{K}$ band characterizes the ratio of the electron transport rates between the donor and acceptor side of PSII and indicates how they operate. The differences in $\mathrm{K}$ band could be positive, due to slower electron transport from the donor side toward PSII reaction centers $\mathrm{P} 60^{+}$(because of OEC inactivation) and/or faster electron withdrawing from the acceptor side, or negative, because of faster electron transport in the donor side (electron transport acceleration) and/or slower withdrawing of electrons from the acceptor side (electron transport delay).

The only positive peak is the K peak in the outer cortex, which indicates that the electron donation from OEC is slower in the cells of the outer layers as compared to A. thaliana plants (Figure 4). The negative values of that band in the inner cortex are a result more of slower electron-withdrawing from the PSII acceptor side than due to the higher rate in the donor side. OEC in the inner cortex works better than the outer one. The negative values for the inner cortex are actually $\mathrm{L}$ band, not a $\mathrm{K}$ peak. The $\mathrm{K}$ peak is not visible. The donor side of the OEC works well, but only the $L$ band of the packaged antenna complexes is revealed. The superposition of the changes in processes leading to $\mathrm{L}$ band formation, and not so much the changes in processes connected to $\mathrm{K}$ band formation, results in the negative values. Thus, the negative values did not mean that the PSII donor side works properly but revealed some electron transport delay in the PSII acceptor side.

\section{$\mathrm{H}$ band (J-I, 2-40 ms)}

J-I transition reflects the dynamics of the PQ pool reduction between the two PS. $\mathrm{H}$ band gives information about the PQ pool volume (number of active PQ molecules functioning between the two PS) and about the electron transfer to $\mathrm{Q}_{\mathrm{A}}{ }^{-}$and the rate of electron withdrawal from $\mathrm{Q}_{\mathrm{A}^{-}}[14,16]$. The electron flow to the end acceptors in PSII strongly correlates with the PQ pool size and the degree of its reduction.

When the PQ pool capacity decreases, the rate of reduction is higher, and this results in positive values of the transient $\mathrm{H}$ band. Conversely, if the relative size of the PQ pool increases, there will be negative values for that band. The $\mathrm{H}$ band represents the dynamics of reduction of PQ pool [16]. Positive differences mean the PQ pool is relatively smaller, and negative means the $P Q$ pool is relatively bigger. Our results showed almost identical negative $\mathrm{H}$ bands for both outer and inner cortices of Smicronix galls, which means the same increase in PQ quantity in comparison to $A$. thaliana leaves. The relative volume of the pool of PSI acceptors increased.

\section{$G$ band ( $(-P, 40-300 \mathrm{~ms})$}

I-P transition gives information about the PSI functioning and reoxidation of the PQ pool from the PSI carriers. The amplitude of the differences (with a maximum at about 150-200 ms) informs about electron transfer between the pool of reduced PQ and the pool of PSI end acceptors (phylloquinone-FeS cluster-ferredoxin-FNR-NADP ${ }^{+}$) [14] and to the relative PSI content [28]. The efficiency of the electron flow and the rate of the reduction of the PSI end electron acceptors determines the shape of the G band. With a larger end acceptors pool, the rising to the maximum will be slower, and this will result in negative values of the transient band. If the pool of PSI end electron acceptors decreases, the transient will be faster, and a positive peak in the DCs will appear. We observed negative $\mathrm{G}$ band values, better pronounced for the inner cortex, which means PSI is more 
active and the relative volume of the end PSI acceptors pool in both gall cortices is bigger than in A. thaliana leaves (Figure 4).

\subsection{JIP-Test Parameters}

JIP-test parameters provide better visualization of the differences between Smicronix galls cortices and the reference plant $A$. thaliana (Figure 5).

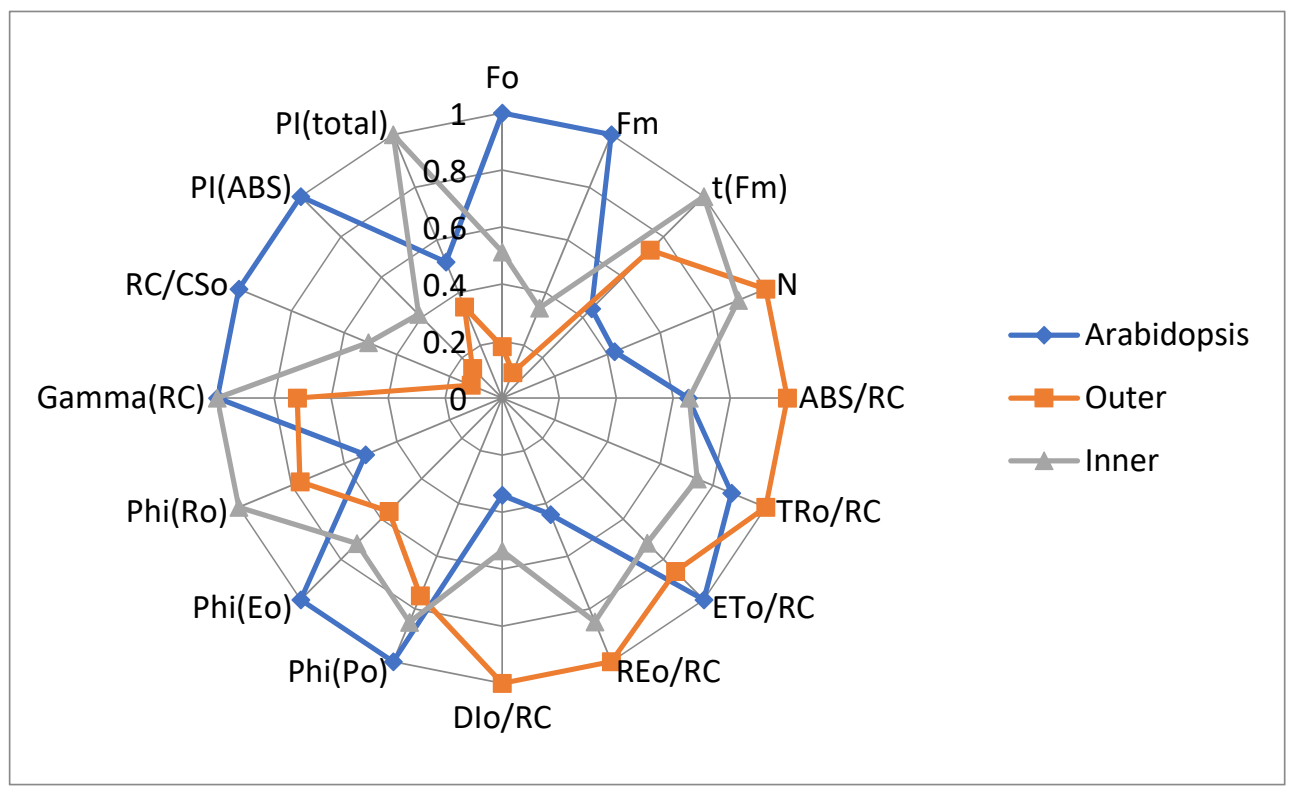

Figure 5. Radar chart of sixteen JIP-parameters calculated from the induction curves of the prompt $\mathrm{Chl}$ a fluorescence in outer and inner cortices of Smicronix galls and in leaves of the reference normal photosynthetic plant $A$. thaliana. The values of each parameter were normalized to the respective maximum.

Lower values of minimal and maximal fluorescence (parameters $F_{o}$ and $F_{m}$ ) in both inner and outer cortices in comparison to the $A$. thaliana leaves are a result of a low density of photosynthetic structures (RC/CSo). The number of RC is especially low in the outer cortex. $\mathrm{N}$, the number of $\mathrm{Q}_{\mathrm{A}}$ redox turnovers until $\mathrm{FM}$ is reached, characterizes the relative size of PQ pool per reaction center. In both cortices, $\mathrm{N}$ is bigger than in $A$. thaliana leaves and a bit smaller in the inner cortex than in the outer; there are PQ molecules, but reaction centers are few.

$\mathrm{ABS} / \mathrm{RC}$ characterizes the size of the PSII antenna complexes. It is bigger in the outer cortex than in the inner one or in A. thaliana leaves. Having bigger antenna complexes in the outer cortex, we can expect more effective energy trapping, but the values of the parameter $\mathrm{TR}_{0} / \mathrm{RC}$ for outer cortex are close to that for $A$. thaliana. Obviously, the energy transfer in the $A$. thaliana PSII antennae is much more effective than in the outer cortex, and especially more effective than in the inner cortex. With a smaller antenna in $A$. thaliana, the efficiency of energy transfer is better than in Smicronix gall cortices. Lower values of $\mathrm{ETo} / \mathrm{RC}$ in gall cortices indicated that the acceptor side in both cortices functions worse than in A. thaliana leaves.

Unlike PSII, PSI works more efficiently in gall cortices (especially in the outer cortex) than in A. thaliana. Arabidopsis values for REo/RC (electron flux reducing end electron acceptors at the PSI acceptor side per PSII reaction center) are much lower than those of Smicronix gall cortices. In general, the energy transfer to RC in gall cortices significantly exceeded the energy transfer in A. thaliana; i.e., the PSA in the reference normal photosynthetic plant operates optimally but is not optimized in Smicronix galls. A lot of excitation energy in gall cortices was dissipated as heat in PSII antennae and reaction centers, especially in the outer cortex (see $\mathrm{DI}_{0} / \mathrm{RC}$ on Figure 5). 
The parameter $\varphi_{\mathrm{E} o}$, the quantum yield for electron transport, shows that the PSII RC worked effectively in the three investigated samples, with maximal efficiency in Arabidopsis leaves, and lower in gall cortices. The differences in $\varphi_{\mathrm{Po}_{0}}$, the maximum quantum yield of primary photochemical reactions in PSII RC, are similar to that for $\varphi_{\text {Eo }}$ but more pronounced for $\varphi_{\mathrm{Eo}}$. The three samples differ in the efficiency of the PSII acceptor side. The differences in the quantum yield of the electron transport from $\mathrm{QA}^{-}$to the end electron acceptors of PSI, $\varphi_{\text {Ro, }}$ also indicated that PSI operates more effectively in cortices than in A. thaliana, and with better effectivity in the inner than in the outer cortex. The energy transformation effectiveness in PSI is almost the same in the two cortices (a bit bigger in the inner cortex) and about 2.5 times lower in A. thaliana (manifested by parameter $\delta_{\text {Ro }}$, efficiency for an electron to move from reduced carriers between the two photosystems to the end acceptors of PSI, $\delta_{\mathrm{Ro}}=\mathrm{RE}_{0} / \mathrm{ET}_{0}$, data not shown). This high efficiency compensates the energy losses in PSII, and the $\varphi_{\text {Ro }}$ values are the biggest in the inner cortex and lowest in A. thaliana.

The density of active PSII reaction centers per cross section (RC/CSo) is very low in both cortices, especially in the outer one. In comparison to $A$. thaliana leaves, it is two times lower in the inner cortex, and about ten times lower in the outer cortex. This affects the PSII efficiency in gall cortices, and their $\mathrm{PI}_{\mathrm{ABS}}$ is very low. $\mathrm{PI}_{\text {total }}$ value in the inner cortex is maximal due to significant compensation from the high efficiency of PSI. In general, the PSA in Smicronix gall cortices is poorly developed quantitatively and qualitatively; not only is the number of structures smaller compared to normal photosynthetic leaves, but also the electron transport chain in galls does not work effectively with regard to PSII. PSI is well developed and works with quite high efficiency. The inner cortex has a higher chlorophyll concentration, and it is photosynthetically more active.

\subsection{Thylakoid Complexes}

To further elucidate the photosynthetic machinery of the Smicronyx galls, we performed solubilization with digitonin and two-dimensional electrophoretic separation (BN PAGE as first dimension, and 15\% T Tricine SDS PAGE as the second dimension). The obtained results are shown in Figure 6. Identification of complexes is based on the comparison to already-published molecular weight of the proteins within the subcomplexes [9] and 2D profiles [17]. Obviously, the number of complexes is fewer in C. campestris than in A. thaliana (Figure 6), but on the other hand, the differences between the inner and outer cortices and the non-photosynthetic stem are not substantial and may differ mainly in the abundance of particular complexes. At least PSI and LHCII were found in C. campestris, but most of the other complexes, identified in A. thaliana, are absent. 


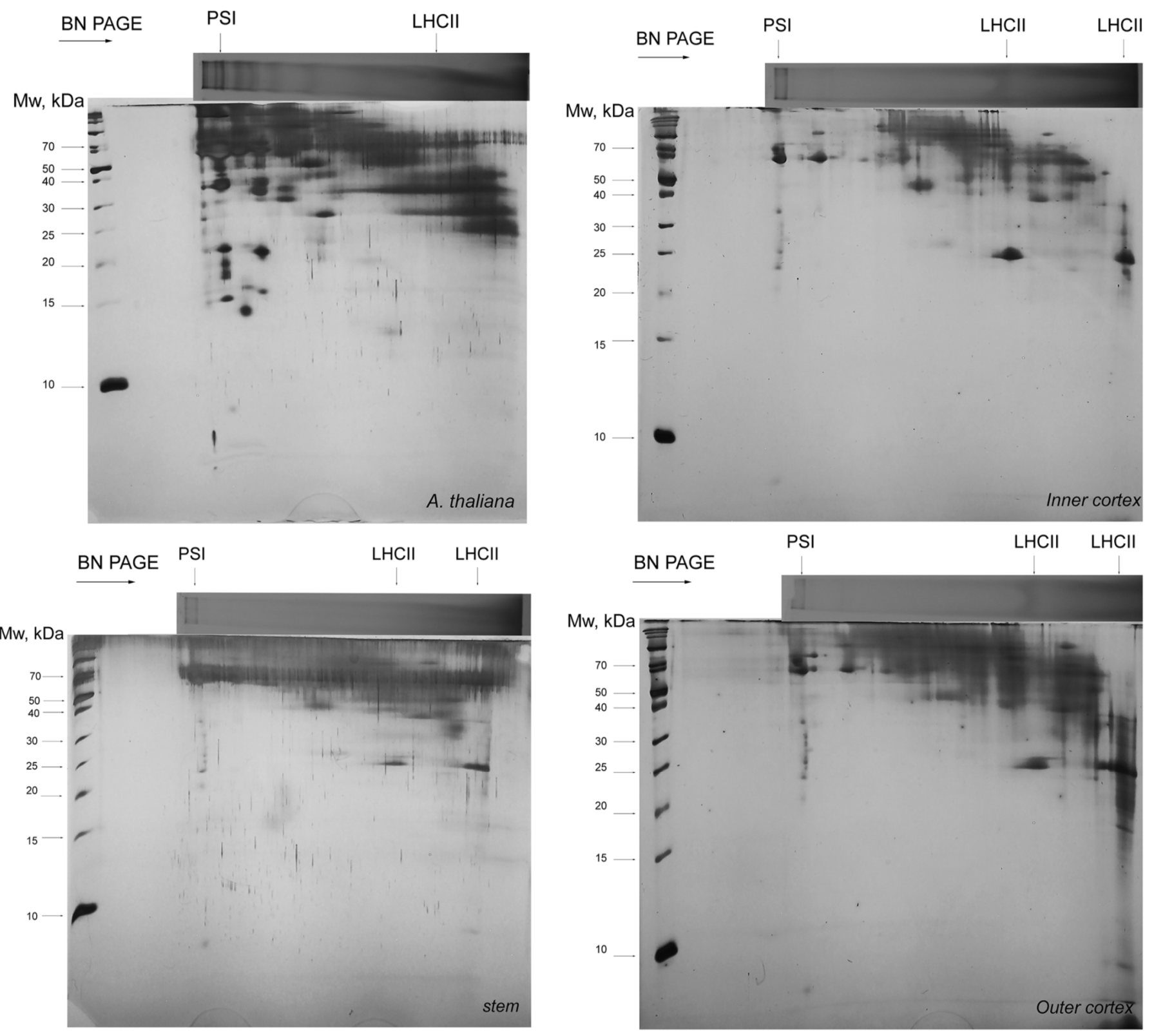

Figure 6. 2D BN/SDS PAGE separation of thylakoid complexes in Arabidopsis thaliana, Cuscuta campestris stem, and Smicronyx galls (inner and outer cortex, respectively). Solubilization with $1 \%$ digitonin. Only the low-molecular-weight standards are indicated.

\section{Discussion}

There are a few investigations in the available literature [11] showing that Smicronix galls have higher $\mathrm{Chl}$ concentration and higher photosynthetic activity in comparison with the Cuscuta stem, and the highest Chl content and the most highly developed chloroplasts were observed in the tissue around the larval chamber. This is probably related to the increased need for nutrients for the developed larvae. The fact the galls have a green color and photosynthetic activity until the larvae are alive supports this hypothesis [11]. When the larva developed and mature weevils left the gall or when larva died (e.g., with Bracon murgabensi infection), the photosynthesis in galls ends. Anikin et al. [11] investigated some parameters of PSII fluorescence in Smicronyx smreczynskii galls on C. campestris and found an increased quantity of active PSII RCs and increased effectiveness of photosynthesis in 
the galls compared to $C$. campestris stems. We further expand this knowledge by studying in detail the parameters of chlorophyll fluorescence by employing the JIP-test (Figures 2-4).

The normal $\mathrm{Chl} \mathrm{a/b}$ ratio in green plants is about 3 . The photosystem II contains three types of light-harvesting complexes: the core antennae containing $\mathrm{Chl}$ a only and most closely associated with the reaction center; the minor $\mathrm{Chl} \mathrm{a/b}$ binding proteins, which occupy an intermediate position between the core antennae and the peripheral antenna; and the outermost $\mathrm{Chl} \mathrm{a/b}$ binding proteins, LHCII [29] and references therein. These three antenna groups account for 14,15 , and $67 \%$, respectively, of the total chlorophyll in PSII; see [30] and references therein. LHCII is the major component of the thylakoid membrane and the major light-harvesting antenna of PSII, with $\mathrm{Chl} \mathrm{a/b}$ ratio close to 1 (8:7 molecules). In addition to harvesting light, LHCII plays a role in membrane stacking, which has consequences in the regulation of the distribution of energy between the two photosystems. The normal Chl a/b ratio in PSI is 5-6. In a previous experiment, we have observed a significant increase in both chlorophyll a and chlorophyll $\mathrm{b}$ concentrations in the Smicronix gall cortices in comparison to the C. campestris stem [12]. Chl a content increased almost twofold in the outer cortex and over threefold in the inner cortex of the gall. Chlorophyll $\mathrm{b}$ was not detected in the non-infected stems, and it was in the highest concentration in the inner cortex. $\mathrm{Chl} \mathrm{a} / \mathrm{b}$ ratio was about 5-6 in the cortices. These results provide indirect evidence that PSI is better organized in galls. Our results from the electrophoretic separation of thylakoid complexes showed much less PSI and LHCII in galls compared to A. thaliana (Figure 6). Unfortunately, with that method, we cannot identify other complexes. The LHCII shortage could result in lesser energy flow toward PSII RC in galls than in A. thaliana. Other authors were also observed low PSII efficiency in C. campestris $[8,31]$. Sherman et al. [32] found that the $C$. pentagona chloroplast contains a number of the proteins required for a successful fixation of $\mathrm{CO}_{2}$ and the proteins in the thylakoids are organized much like other higher plants, with the exception of the large percentage of the thylakoids organized into grana.

As we demonstrated, C. campestris, under certain circumstances (i.e., in the Smicronyx galls) is able to properly arrange its photosynthetic machinery and to perform sufficient photosynthesis (Figure 2). This is not an exception in nature. Many plants are able to turn heterotrophic organs (roots) green. It is considered to contribute to the carbon economy of the whole plant ([33] and references therein). A. thaliana roots also have the potential to synthetize chlorophyll and to develop chloroplasts under light, with phytohormone signaling involved. The process is more effective when the shoots have been removed. The O-J-I-P transients were observed in root samples, indicating the presence of functional electron transport in PSII. The PSII efficiency was lower than in the shoot chloroplasts, and the electron transport from $\mathrm{Q}_{\mathrm{A}}{ }^{-}$to $\mathrm{Q}_{\mathrm{B}}$ was slowed down in the root plastids. The roots demonstrate accelerated chlorophyll accumulation and chloroplast development when they are detached from shoots. The authors concluded that the increased photosynthesis by "green roots" could contribute to the carbon economy of the whole plant [33]. The induction of chlorophyll synthesis and chloroplasts development in infected C. campestris plants might be related to the increased need for carbohydrates for the Smicronyx larvae nutrition [12]. The major differences, predetermining the increased and more efficient photosynthesis in the galls as compared to the stem are not in the thylakoid complexes (Figure 6) but probably in the chlorophyll concentration [12]. It was reported that most of the photosynthetic proteins are present in C. campestris, at least at a gene level [6], but still, they are underrepresented even in the inner gall cortex as compared to Arabidopsis thaliana.

Photosynthesis may vary significantly between Cuscuta species [5,34,35], but C. campestris is among the better photosynthetizers in the genus [8]. This capacity may further vary depending on environmental factors, including the presence of Smicronyx galls. Its inability to function as an independent/self-reliant plant is a result of the non-functional roots [6, 32,36], but also of the lack of developed leaves, which limits the surface available for light absorption. Most importantly, the stem of Cuscuta spp., and C. campestris stem in particular, has low chlorophyll concentration [12,34] but is very rich in carotenoids, especially lutein-5, 
6-epoxide, and 9-cis-violaxanthin [37,38], which is important in photoprotection. This might be also beneficial for the Smicronyx larvae, ensuring its protection from high light intensity by the outer cortex of the gall.

However, is the formation of the gall detrimental or beneficial to the parasitic plant? Some authors suggest a new view of the relationship between Smicronyx and Cuscuta-not epiparasitism, but a mutually beneficial interaction between the species [11]. Although the impact of the insect larvae did not seem to be negative in the gall itself-photosynthesis is enhanced and no significant oxidative stress was found [12], it may be negative at the individual plant level, as other reports showed the galls could restrict the flow of nutrients to the flowers of Cuscuta, thus limiting the number of viable seeds [39].

\section{Conclusions}

The infection of Smicronyx on C. campestris leads to the development of galls with morphologically and functionally distinct inner and outer cortices. Our results showed some photosynthetic activity in the gall cortices, which were more effective in the inner one. It is a result mainly of increased chlorophyll $a$ concentration rather than qualitative changes in the thylakoid complexes. No apparent differences were found in the number of identified thylakoid complexes between the gall cortices and C. campestris stem, although the abundance in the stem seemed to be lower. The higher chlorophyll concentration in the inner cortex and the higher photosynthetic activity are related to its main function as a direct nutritional source for the larvae. The outer cortex probably has a more protective function. We consider the insect-triggered transition from non-photosynthetic to photosynthetic tissue in the gall to be driven by increased nutrient requirements associated with larval feeding. This induced photosynthesis did not reach the levels of the photosynthetic activity in Arabidopsis thaliana plants.

Author Contributions: Conceptualization, L.Z., V.G., and H.M.K.; methodology, V.G., M.K., and P.M.; experimentation, A.A., I.A., A.T., and P.M.; data analyses, D.T., V.G., P.M., and M.K.; writing-L.Z., M.K., H.M.K., and D.T. All authors have read and agreed to the published version of the manuscript.

Funding: This research was financially supported by grant KP-06-N31/10 of the National Science Fund, Ministry of Education and Science, Bulgaria.

Institutional Review Board Statement: Not applicable.

Informed Consent Statement: Not applicable.

Data Availability Statement: Not applicable.

Conflicts of Interest: The authors declare no conflict of interest.

\section{Abbreviations}

Chl: chlorophyll; DC: different curves; IC: induction curves; OEC: oxygen-evolving complex; $\mathrm{PF}$ - prompt chlorophyll $a$ fluorescence; PSA: photosynthetic apparatus; PS (I, II): photosystem (I, II), PQ: plastoquinone, RC: reaction center. 


\section{Appendix A}

Table A1. Definition of selected OJIP parameters according to Strasser et al. [14] and Stirbet and Govindjee [15].

\begin{tabular}{|c|c|}
\hline Parameter & Definition \\
\hline $\mathrm{F}_{\mathrm{O}}$ & $\begin{array}{l}\text { Minimal fluorescence, when all PSII reaction centers (RCs) are open, fluorescence intensity } \\
\text { at } 20 \text { th } \mu \text { s }\end{array}$ \\
\hline $\mathrm{F}_{\mathrm{M}}=\mathrm{F}_{\mathrm{P}}$ & $\begin{array}{l}\text { Maximal fluorescence recorded under saturating illumination at the peak P of OJIP, when } \\
\text { all PSII RCs are closed }\end{array}$ \\
\hline $\mathrm{F}_{\mathrm{J}}(2 \mathrm{~ms})$ & Fluorescence level at 2nd ms, the J-step of OJIP \\
\hline $\mathrm{F}_{\mathrm{I}}(40 \mathrm{~ms})$ & Fluorescence level at 40th ms, the I-step of OJIP на грачиката е 40-та ms \\
\hline $\mathrm{F}_{\mathrm{V}}$ & Maximal variable fluorescence, $F_{V}=F_{M}-F_{O}$ \\
\hline $\mathrm{V}_{\mathrm{t}}$ & Relative variable fluorescence at time $t: \mathrm{V}_{\mathrm{t}}=\left(\mathrm{F}_{\mathrm{t}}-\mathrm{F}_{\mathrm{O}}\right) /\left(\mathrm{F}_{\mathrm{M}}-\mathrm{F}_{\mathrm{O}}\right)$ \\
\hline $\mathrm{V}_{\mathrm{L}}$ & Relative fluorescence value at L-step [0.15 ms] \\
\hline $\mathrm{V}_{\mathrm{K}}$ & Relative fluorescence value at K-step [0.3 ms] \\
\hline $\mathrm{N}$ & $\begin{array}{l}\text { Number indicating how many times } Q_{A} \text { is reduced until fluorescence reaches its maximal } \\
\text { value } F_{M} \text { (number of } Q_{A} \text { redox turnovers until } F_{M} \text { is reached) }\end{array}$ \\
\hline ABS & Absorbed energy flux (exited PSII antennae Chl $a$ molecules) \\
\hline $\mathrm{TR}_{0}$ & $\begin{array}{l}\text { Trapped energy, i.e., energy, utilized for reduction of pheophytin and primary quinone } \\
\text { acceptor } Q_{A}\end{array}$ \\
\hline $\mathrm{ET}_{0}$ & Electron transport from $\mathrm{Q}_{\mathrm{A}}{ }^{-}$to the next electron acceptors between the two photosystems. \\
\hline $\mathrm{RE}_{0}$ & $\begin{array}{l}\text { Energy/electron flux for reduction of end acceptors in acceptor side of PSI-NADP and } \\
\text { ferredoxin. }\end{array}$ \\
\hline$\varphi_{\mathrm{Eo}}\left(\mathrm{ET}_{0} / \mathrm{ABS}\right)$ & $\begin{array}{l}\text { Efficiency/probability for the electron in PSII to move further than } \mathrm{Q}_{\mathrm{A}}{ }^{-}-\text {quantum yield for } \\
\text { electron transport. } \\
\qquad \varphi_{\mathrm{Eo}}=\mathrm{ET}_{0} / \mathrm{ABS}=\varphi_{\mathrm{Po}} \times \psi_{0}=\left(1-\mathrm{F}_{0} / \mathrm{F}_{\mathrm{M}}\right) \times \psi_{0}\end{array}$ \\
\hline $\mathrm{ABS} / \mathrm{RC}$ & $\begin{array}{l}\text { Absorbed energy flux in antenna chlorophylls per PSII reaction center } \\
\text { (a measure of PSII apparent antenna size) }\end{array}$ \\
\hline $\mathrm{TR}_{0} / \mathrm{RC}$ & Trapped energy flux per $\mathrm{RC} ; \mathrm{TR}_{0} / \mathrm{RC}=\mathrm{M}_{0}\left(1 / \mathrm{V}_{\mathrm{J}}\right)$ \\
\hline $\mathrm{ET}_{0} / \mathrm{RC}$ & Electron transport flux further than $\mathrm{Q}_{\mathrm{A}^{-}}$per PSII reaction center \\
\hline $\mathrm{RE}_{0} / \mathrm{RC}$ & $\begin{array}{l}\text { Electron flux reducing end electron acceptors at the PSI acceptor side, per PSII } \\
\text { reaction center }\end{array}$ \\
\hline $\mathrm{DI}_{0} / \mathrm{RC}$ & Heat dissipation of excitation energy by PSII reaction center \\
\hline $\mathrm{ET}_{0} / \mathrm{RC}$ & Electron transport flux further than $\mathrm{Q}_{\mathrm{A}}{ }^{-}$per PSII reaction center \\
\hline$\varphi_{\text {Po }}\left(\mathrm{TR}_{0} / \mathrm{ABS}\right)$ & $\begin{array}{l}\text { Maximum quantum yield of primary photochemical reactions in PSII RC. } \\
\qquad \varphi_{\mathrm{Po}}=\mathrm{TR}_{0} / \mathrm{ABS}=1-\mathrm{F}_{\mathrm{O}} / \mathrm{F}_{\mathrm{M}}=\mathrm{F}_{\mathrm{V}} / \mathrm{F}_{\mathrm{M}}\end{array}$ \\
\hline$\varphi_{\mathrm{Ro}}\left(\mathrm{RE}_{0} / \mathrm{ABS}\right)$ & $\begin{array}{l}\text { Quantum yield of the electron transport from } \mathrm{Q}_{\mathrm{A}}^{-} \text {to the end electron acceptors of PSI } \\
\qquad \mathrm{RE}_{0} / \mathrm{ABS}=\varphi_{\mathrm{Ro}}=\varphi_{\mathrm{Po}} \times \psi_{0} \times \delta_{0}\end{array}$ \\
\hline $\mathrm{RC} / \mathrm{CS}_{0}$ & $\begin{array}{l}\text { Density of active PSII reaction centers }(\mathrm{RC}) \text { per cross section } \mathrm{RC} / \mathrm{CS}_{0}=\varphi_{\mathrm{Po}} \times\left(\mathrm{V}_{\mathrm{J}} / \mathrm{M}_{0}\right) \times \\
\left(\mathrm{ABS} / \mathrm{CS}_{0}\right)\end{array}$ \\
\hline $\mathrm{PI}_{\mathrm{ABS}}$ & $\begin{array}{c}\text { Performance index (potential) for conservation of the energy absorbed by PSII RC until the } \\
\text { reduction of intersystem electron acceptors }\end{array}$ \\
\hline $\mathrm{PI}_{\text {total }}$ & $\begin{array}{l}\text { Performance index (potential) for conservation of the energy absorbed by PSII until the } \\
\text { reduction of PSI end electron acceptors }\end{array}$ \\
\hline
\end{tabular}

\section{References}

1. Parker, C. Parasitic weeds: A world challenge. Weed Sci. 2012, 60, 269-276. [CrossRef]

2. Kim, G.; Westwood, J.H. Macromolecule exchange in Cuscuta-host plant interactions. Curr. Opin. Plant Biol. 2015, 26, 20-25. [CrossRef] 
3. Revill, M.J.; Stanley, S.; Hibberd, J.M. Plastid genome structure and loss of photosynthetic ability in the parasitic genus Cuscuta. J. Exp. Bot. 2005, 56, 2477-2486. [CrossRef]

4. Funk, H.T.; Berg, S.; Krupinska, K.; Maier, U.G.; Krause, K. Complete DNA sequences of the plastid genomes of two parasitic flowering plant species, Cuscuta reflexa and Cuscuta gronovii. BMC Plant Biol. 2007, 7, 1-12. [CrossRef]

5. McNeal, J.R.; Kuehl, J.V.; Boore, J.L.; de Pamphilis, C.W. Complete plastid genome sequences suggest strong selection for retention of photosynthetic genes in the parasitic plant genus Cuscuta. BMC Plant Biol. 2007, 7, 1-22. [CrossRef]

6. Braukmann, T.; Kuzmina, M.; Stefanović, S. Plastid genome evolution across the genus Cuscuta (Convolvulaceae): Two clades within subgenus Grammica exhibit extensive gene loss. J. Exp. Bot. 2013, 64, 977-989. [CrossRef]

7. Vogel, A.; Schwacke, R.; Denton, A.K.; Usadel, B.; Hollmann, J.; Fischer, K.; Bolger, A.; Schmidt, M.H.-W.; Bolger, M.E.; Gundlach, H. Footprints of parasitism in the genome of the parasitic flowering plant Cuscuta campestris. Nat. Commun. 2018, 9, 2515. [CrossRef] [PubMed]

8. Van der Kooij, T.; Krause, K.; Dörr, I.; Krupinska, K. Molecular, functional and ultrastructural characterisation of plastids from six species of the parasitic flowering plant genus Cuscuta. Planta 2000, 210, 701-707. [CrossRef]

9. Aistova, E.; Bezborodov, V. Weevils belonging to the Genus Smicronyx Schönherr, 1843 (Coleoptera, Curculionidae) affecting dodders (Cuscuta Linnaeus, 1753) in the Russian Far East. Russ. J. Biol. Invasions 2017, 8, 184-188. [CrossRef]

10. De Oliveira, D.C.; Moreira, A.S.F.P.; dos Santos Isaias, R.M. Functional gradients in insect gall tissues: Studies on Neotropical host plants. In Neotropical Insect Galls; Springer: New York, NY, USA, 2014; pp. 35-49.

11. Anikin, V.; Nikelshparg, M.; Nikelshparg, E.; Konyukhov, I. Photosynthetic activity of the dodder Cuscuta campestris (Convolvulaceae) in case of plant inhabitation by the gallformed weevil Smicronyx smreczynskii (Coleoptera, Curculionidae). Izv. Saratov Univ. New Ser. Chem. Biol. Ecol. 2017, 17, 42-47.

12. Zagorchev, L.I.; Albanova, I.A.; Tosheva, A.G.; Li, J.; Teofanova, D.R. Metabolic and functional distinction of the Smicronyx sp. galls on Cuscuta campestris. Planta 2018, 248, 591-599. [CrossRef] [PubMed]

13. Zhekova, E.; Petkova, D.; Ivanova, I. Smicronyx smreczynskii F. Solari, 1952 (Insecta: Curculionidae): Possibilities for biological control of two Cuscuta species (Cuscutaceae) in district of Ruse. Acta Zool. Bulg. 2014, 66, 431-432.

14. Strasser, R.J.; Tsimilli-Michael, M.; Srivastava, A. Analysis of the chlorophyll a fluorescence transient. In Chlorophyll a Fluorescence; Springer: New York, NY, USA, 2004; pp. 321-362.

15. Stirbet, A.; Govindjee. Chlorophyll $a$ fluorescence induction: A personal perspective of the thermal phase, the J-I-P rise. Photosynth. Res. 2012, 113, 15-61. [CrossRef] [PubMed]

16. Dimitrova, S.; Paunov, M.; Pavlova, B.; Dankov, K.; Kouzmanova, M.; Velikova, V.; Tsonev, T.; Kalaji, H.; Goltsev, V. Photosynthetic efficiency of two Platanus orientalis L. ecotypes exposed to moderately high temperature-JIP-test analysis. Photosynthetica 2020, 58, 657-670. [CrossRef]

17. Järvi, S.; Suorsa, M.; Paakkarinen, V.; Aro, E.-M. Optimized native gel systems for separation of thylakoid protein complexes: Novel super-and mega-complexes. Biochem. J. 2011, 439, 207-214. [CrossRef] [PubMed]

18. Kügler, M.; Jänsch, L.; Kruft, V.; Schmitz, U.K.; Braun, H.-P. Analysis of the chloroplast protein complexes by blue-native polyacrylamide gel electrophoresis (BN-PAGE). Photosynth. Res. 1997, 53, 35-44. [CrossRef]

19. Schägger, H.; von Jagow, G. Tricine-sodium dodecyl sulfate-polyacrylamide gel electrophoresis for the separation of proteins in the range from 1 to $100 \mathrm{kDa}$. Anal. Biochem. 1987, 166, 368-379. [CrossRef]

20. Tsimilli-Michael, M.; Strasser, R.J. The energy flux theory 35 years later: Formulations and applications. Photosynth. Res. 2013, 117, 289-320. [CrossRef]

21. Stirbet, A. Excitonic connectivity between photosystem II units: What is it, and how to measure it? Photosynth. Res. 2013, 116, 189-214. [CrossRef]

22. Strasser, R.J.; Stirbet, A.D. Estimation of the energetic connectivity of PS II centres in plants using the fluorescence rise O-J-I-P: Fitting of experimental data to three different PS II models. Math. Comput. Simul. 2001, 56, 451-462. [CrossRef]

23. Srivastava, A.; Strasser, R.J. Stress and stress management of land plants during a regular day. J. Plant Physiol. 1996, 148, 445-455. [CrossRef]

24. Srivastava, A.; Guisse, B.; Greppin, H.; Strasser, R.J. Regulation of antenna structure and electron transport in photosystem II of Pisum sativum under elevated temperature probed by the fast polyphasic chlorophyll $a$ fluorescence transient: OKJIP. Biochim. Biophys. Acta (BBA) Bioenerg. 1997, 1320, 95-106. [CrossRef]

25. Strasser, B.J. Donor side capacity of photosystem II probed by chlorophyll a fluorescence transients. Photosynth. Res. 1997, 52, 147-155. [CrossRef]

26. Stirbet, A.; Riznichenko, G.Y.; Rubin, A. Modeling chlorophyll $a$ fluorescence transient: Relation to photosynthesis. Biochemistry 2014, 79, 291-323. [CrossRef] [PubMed]

27. Guisse, B.; Srivastava, A.; Strasser, R. The polyphasic rise of the chlorophyll $a$ fluorescence (OKJIP) in heat-stressed leaves. Arch. Sci. 1995, 48, 147-160.

28. Ceppi, M.G.; Oukarroum, A.; Çiçek, N.; Strasser, R.J.; Schansker, G. The IP amplitude of the fluorescence rise OJIP is sensitive to changes in the photosystem I content of leaves: A study on plants exposed to magnesium and sulfate deficiencies, drought stress and salt stress. Physiol. Plant. 2012, 144, 277-288. [CrossRef] [PubMed]

29. Blankenship, R.E. Molecular Mechanisms of Photosynthesis; Wiley-Blackwell Publisher: Chichester, West Sussex, UK, $2014 ;$ p. 312.

30. Ke, B. Photosynthesis: Photobiochemistry and Photobiophysics; Kluwer Academic Publishers: Dordrecht, The Netherlands, 2001. 
31. Dinelli, G.; Bonetti, A.; Tibiletti, E. Photosynthetic and accessory pigments in Cuscuta campestris Yuncker and some host species. Weed Res. 1993, 33, 253-260. [CrossRef]

32. Sherman, T.D.; Pettigrew, W.T.; Vaughn, K.C. Structural and immunological characterization of the Cuscuta pentagona L. chloroplast. Plant Cell Physiol. 1999, 40, 592-603. [CrossRef]

33. Kobayashi, K.; Baba, S.; Obayashi, T.; Sato, M.; Toyooka, K.; Keranen, M.; Aro, E.-M.; Fukaki, H.; Ohta, H.; Sugimoto, K.; et al. Regulation of root greening by light and auxin/cytokinin signaling in Arabidopsis. Plant Cell 2012, 24, 1081-1095. [CrossRef]

34. Machado, M.; Zetsche, K. A structural, functional and molecular analysis of plastids of the holoparasites Cuscuta reflexa and Cuscuta europaea. Planta 1990, 181, 91-96. [CrossRef]

35. McNeal, J.R.; Arumugunathan, K.; Kuehl, J.V.; Boore, J.L.; Claude, W.D. Systematics and plastid genome evolution of the cryptically photosynthetic parasitic plant genus Cuscuta (Convolvulaceae). BMC Biol. 2007, 5, 1-19. [CrossRef]

36. Jadhav, S.; Toro, S. Vestigial root structure of Cuscuta reflexa and C. chinensis. BIOINFOLET-A Q. J. Life Sci. 2020, $17,53-55$.

37. Snyder, A.M.; Clark, B.M.; Bungard, R.A. Light-dependent conversion of carotenoids in the parasitic angiosperm Cuscuta reflexa L. Plant Cell Environ. 2005, 28, 1326-1333. [CrossRef]

38. Snyder, A.M.; Clark, B.M.; Robert, B.; Ruban, A.V.; Bungard, R.A. Carotenoid specificity of light-harvesting complex II binding sites: Occurrence of 9-cis-violaxanthin in the neoxanthin-binding site in the parasitic angiosperm Cuscuta reflexa. J. Biol. Chem. 2004, 279, 5162-5168. [CrossRef] [PubMed]

39. Toth, P.; Tothova, M.; Cagáň, L. Potential biological control agents of field bindweed, common teasel and field dodder from Slovakia. In Proceedings of the 12th International Symposium on Biological Control of Weeds, La Grande Motte, France, 22-27 April 2008; pp. 216-220. 